\title{
Componentes del latinoamericanismo en Manuel Ugarte
}

\author{
IsidRo Sepúlveda MuÑoz
}

Los planteamientos ideológicos sobre la división nacional del territorio americano nacen - y son al tiempo agentes operativos- en los mismos años del proceso independentista. En ese momento existen tres concepciones de lo que el Nuevo Mundo debía llegar a ser: la idea unionista, que se podría personalizar en Bolívar (aunque no fuera su principal promulgador teórico) ${ }^{\natural}$; la evolución de la política exterior de Estados Unidos con respecto a América, que en los años veinte llegó a su plasmación más trascendente en la doctrina Monroe y a final de siglo en la materialización oficial del panamericanismo ${ }^{2}$; y la concepción que, en

1 En la heterogénea idea unionista estaban integrados entre otros San Martín, Castelli, Martínez de las Rozas, Juan Egaña, Bernardo Monteagudo, etc. Estudiando los esquemas e ideales políticos de cada uno de ellos se llega a la conclusión de que no existian dos planteamientos semejantes (desde el jacobinismo de Francisco de Miranda a los realistas Miyares y Cajigal), sin que nadie - ni el mismo Bolivar- pudiera imponer su idea.

${ }^{2}$ La Unión Panamericana mantiene sistemáticamente que el origen del movimiento panamericanista corresponde al «libertador Simón Bolívar como primer anunciador» (v. Instituto Panamericano de Geografía e Historia: Breve reseña histórica del movimiento panamericanista. Washington 1940). Muy al contrario, en los primeros años del siglo XIX, Hamilton ya declaraba la intención de formar un sistema americano autónomo, sin influencias europeas, dando por supuesto que la dirección por "derecho de situación" correspondía a Estados Unidos. En los momentos que se luchaba en las guerras de emancipación, Thomas Jefferson propuso crear un sistema americano separado de Europa, con Estados Unidos como hacedor e intermediario de las partes. En 1812, Sheiller -encargado de negocios en Nueva España- presentó un plan que dividía todo el territorio al sur de Río Grande en cinco estados, "protegidos" por Estados Unidos. A las directrices políticas, estratégicas y militares ya apuntadas, se añadió en 1820 la pretensión de Henry Clay -Presidente de la Cámara de Representantes- que llenó de contenido económico esa perseguida dirección continental: capitalizando los intercambios entre Europa y América, Estados Unidos se convertiría en el centro del mercado mundial, apoyado por una creciente flota mercante y la más poderosa armada. Todo esto antes que Monroe públicamente diera a conocer las famosas determinaciones.- v. J. B. LOCHEY: Essays in Pan-Americanism. Berkeley 1939. A. P. WHITAKER: The United States and the Independence of Latin America, 1800-1830. New York 1962. 
definitiva, conseguirá imponer su planteamiento basado en la política de los hechos consumados: la política nacionalista de separación provincial $^{3}$.

Las turbulentas vicisitudes de la política americana siguieron su curso, más llevadas por impulsos personales e intereses económicos que por programas ideológicos dignos de tal nombre. De hecho, cincuenta años después de la muerte de Bolívar las fronteras no sólo se habian levantado, sino que se fortificaban más cada día, las banderas remarcaban con su tremolar colorido las diferencias y los himnos nacionales cubrían de orgullo patrio a los ciudadanos de unos y otros Estados. Aunque no a todos.

A finales del pasado siglo inician una afloración movimientos unionistas de diferente signo. Las causas de este resurgimiento encuentran paralelismos con ideas nacionalistas que habían recorrido Europa; la evolución del liberalismo, la eclosión romántica, las reunificaciones italiana y alemana inciden en América potenciando un movimiento general en el que por primera vez se cuestiona la identidad de los Estados, paradójicamente en busca de una personalidad que no fuera simple reflejo europeo. Esto lleva, a su vez, a establecer un nuevo conflicto al plantearse el deslinde entre la herencia indigenista, el muy presente sustrato español y la recreación y logros que en cada una de las repúblicas se habían llevado a cabo desde la independencia.

En consecuencia, era una reflexión sobre la cultura y la identidad nacional. Siguiendo la cita de Heidegger, «reflexionar es tener el coraje de convertir la verdad de los propios presupuestos y el ámbito de los propios fines en objeto de atención", esta reflexión de fronteras a dentro conduce a conclusiones que trascienden aquellas para convertirse en propuestas continentales. Con prólogos reales en los levantamientos de Felipe Varela, proclamando la Unión Americana, o de López Jordán persiguiendo la «indisoluble y santa confraternidad americana», es la época en que aparecen La americanización del mundo de Blanco Fombona, La ilusión americana, de Pedro Padro, Ariel, de Rodó, Ante los bárbaros, de

${ }^{3}$ Se ha señalado la existencia de uria cuarta corriente, que podría denominarse "vjrreinal», en pro de una defensa de los límites y fronteras de los virreinatos de la corona española (v. O. C. Stoetzer: El pensamiento político en la América española durante el periodo de la emancipación (1789-1825). Madrid 1966, Centro de Estudios Constitucionales). En realidad esta corriente es sólo una variante "confederada» de la primera, siendo sus integrantes en alguna ocasión parte de ella. 
Vargas Villa, o El continente enfermo, de Cesar Zumeta. Es también el momento en que eclosiona la argentina generación del 900 , dando origen a un grupo humano, no homogéneo pero de consideraciones e intereses coincidentes, cuya repercusión llegó a todo el continente: Alberto Ghiraldo, José Ingenieros o Leopoldo Lugones, entre otros, buscando la "Grande Argentina» llegaron a la respuesta de América ${ }^{4}$. En esta generación del 900 se encuadra, aunque con plateamientos y conclusiones que trascienden su época, la figura de Manuel Baldomero Ugarte.

\section{LATINOAMERICANISMO}

Ugarte publicó treinta y siete obras de poesía, narración, crónica de viajes y ensayo; si las primeras, escasas y sin pretensiones, no han tenido demasiada estima en la historia de la literatura, y no mucho más las segundas, su aportación en el campo de las ideas destaca con nitidez, no sólo a nivel personal sino en toda la historia del pensamiento político americano. Artículos periodísticos y transcripciones de conferencias y discursos son reunidos y publicados junto a obras nucleares en una serie de libros que plasman de modo concreto la idea del futuro americano en lo que él llama la Patria Grande. Esta idea no es otra que la unión de todos los Estados de cultura ibera:

«Patria Grande tiene dos significados: geográficamente sirve para designar el conjunto de todas las repúblicas de tradición y civilización ibérica. Desde el punto de vista cultural, evoca, dentro de cada una de

${ }^{4}$ Paralela a la española del 98, en Argentina se desarrolla la generación del 900, que partiendo de causas y orígenes diferentes alcanzan planteamientos en algunos casos muy semejantes: la búsqueda de una identidad nacional enlaza y se confunde con la introspección personal. Macedonio Fernández encuentra una respuesta en el cinismo distanciador frente a la sociedad dirigida por compañías extranjeras; Manuel Gálvez se refugia en el catolicismo tras abandonar el socialismo ateo que profesó en su juventud; A. GHIRALDo, autor de Yanquilandia bárbara y La tiranía del frac, mantuvo su anarquismo frente a las potencias comerciales transatlánticas, lo que le llevó al exilio y a la digna muerte de un abandonado solitario; José Ingenieros, quien más cerca de la política activa estuvo, acabó desengañado de la realidad de su país, recluyéndose en sus libros y el estudio de la psicología; Leopoldo Lugones, como Ingenieros, comprendió las posibilidades del socialismo popular con especificidades nacionales, pero desembocó en un liberalismo reaccionario que le llevó al fascismo; Ricardo Rojas buscando el engrandecimiento futuro reivindica la «argentinidad", pero cae en el indigenismo cerrado y el particularismo arcaizante. 
las divisiones actuales, la elevación de propósitos y la preocupación altamente nacionalista. Si deseamos conquistar para nuestro núcleo la más alta situación posible, tenemos que conseguir los dos empeños a la vez" ${ }^{5}$.

El joven aprendiz de poeta que a los diecinueve años funda la $R e-$ vista Literaria con la pretensión de ser un vehículo de unión para todos los escritores de América, se ve empujado en su ansia de conocimiento al París de la Exposición Universal finisecular. Es allí, lejos de lo que llama Patria Chica, asombrándose de que un notable intelectual francés asegure a Río de Janeiro como capital argentina, donde descubre la nimiedad de las diferencias que tan importantes le parecieron; donde comprende la posibilidad, y posteriormente sienta la necesidad, de reunificar ese todo homogéneo. Este descubrimiento lo empuja a un estudio apasionado de la historia y a interesarse por la joven sociología ${ }^{6}$.

Parte de la pregunta: ¿cada uno de los territorios que encierran las actuales fronteras puede considerarse y llegar a ser una nación o ésta es la Patria Grande que ha sido atomizada artificialmente? No es un planteamiento nuevo, ni será Ugarte el último que lo establezca; su originalidad reside en la respuesta completa y en la concreción de planteamientos como medios para conseguir la reunificación. En primer lugar aparecen los argumentos reiterados por todos los publicistas del americanismo: la confluencia de expresión en un mismo idioma, la población de un territorio común, un semejante origen colonizador, una serie de héroes comunes y unos tradicionales vínculos económicos que por dis-

${ }^{5}$ Prólogo a la segunda edición de La Patria Grande; Buenos Aires 1922, Editora Internacional.

${ }^{6}$ El proceso de aprendizaje por el que partiendo de una curiosidad sobre la historia nacional llega al estudio de la emancipación y evolución política americana, se narra en el capítulo primero --titulado «El lobo y los corderos»- de El destino de un continente. Madrid 1923, Ed. Mundo Latino. En el se encuentra a este esclarecedor párrafo: "Así fui aprendiendo, al par que la historia del imperialismo, nuestra propia historia hispano-americana en la amplitud de sus consecuencias y en su filosofía actual. Lo que habia aprendido en la escuela, era una interpretación regional y mutilada, [...] una crónica local donde predominaba la anécdota, sin que llegara a surgir de los nombres y las fechas una concepción superior, un criterio analítico o una percepción clara de los que el fenómeno significaba para América y para el mundo. $Y$ con el conocimiento de la historia común, venía una amarga tristeza de comprender que nuestros males eran obra, más que de la avidez de los extraños, de nuestra incapacidad para la lucha, de nuestra falta de conocimiento de las leyes sociológicas, de nuestra visión estrecha y ensimismada, de nuestra dispersión y nuestro olvido de los intereses trascendentales». 
minuidos en su tiempo pueden retomar y aumentar en importancia a los del período de la corona española ${ }^{7}$.

Antes de matizar los componentes de su pensamiento americanista, es preciso puntualizar dos aspectos de éste, si bien no imprescindibles sí importantes en la exposición posterior: el uso del término «latinoamericanismo» y el papel que Ugarte reservaba a España en la futura unión americana. La utilización de latinoamericanismo para designar la pertenencia al mundo de tradición y cultura hispana en América, en oposición al mundo anglosajón, era de uso común en los intelectuales y gobernantes americanos de finales de siglo; sin entrar en el origen y proyecto de política exterior resultante que tiene tal concepto, se debe señalar que la designación de las tierras al sur del Río Grande era muy variada, en muchos casos siguiendo de modo puntual las denominaciones europeas, pero generalmente sin imprimirles las connotaciones de prestigio y propaganda con que fueron bautizadas. Por otro lado, Ugarte utiliza con sorprendente variabilidad los términos América Latina, Iberoamérica y América Española, sin entrar en ninguna ocasión a justificar su uso ni estudiar las diferencias ${ }^{8}$.

La unión americana para Ugarte es una América sin fronteras, sin injerencias exteriores pero reconocedora y orgullosa de su pasado. Lejos de las imágenes que aigunos americanistas españoles pretendían otorgar a España como cabeza de un movimiento panibérico con evidente - $\mathrm{e}$ inevitable - extensión americana, Ugarte no concede a España una importancia básica en ese movimiento; no por resentimiento atávico o negación filial, sino por conocimiento del papel real que la política española podía jugar en el exterior. Culturalmente ocuparía la cabeza de un grupo de naciones europeas (Portugal, Francia e Italia) sobre las que debería apoyarse el movimiento unificador, bien consciente de que cuanto más

${ }^{7}$ En oposición a otros publicistas, Ugarte no estima el vínculo común de la práctica católica, hecho que sólo puede ser justificado por su militancia socialista; más adelante, cuando en sus planteamientos aparezcan los protestantes norteamericanos, rescatará esta faceta diferenciadora.

${ }^{B}$ Los ejemplos son abundantes y pueden verse en las citas incluidas en este artículo. En los títulos de sus obras, Ugarte juega con estas fórmulas: El porvenir de la América Española, Valencia 1910, Prometeo Editor; fue también publicado bajo el título de El porvenir de la América Latina. Doce años después publica Mi campaña Hispanoamericana, Barcelona 1922, Editorial Cervantes. En 1940 publica un artículo con el nombre «Estado social de Iberoamérica"; y ante la Segunda Guerra Mundial, una serie de artículos fueron reunidos bajo un título manifiesto: "No soy aliadófilo, ni germanófilo: soy iberoamericano"; La nación Latinoamericana, Caracas 1978, Biblioteca Ayacucho, 45. 
identificados con sus comunes raíces pasadas estuvieran los americanos más fácil sería el retorno a esa unión ${ }^{9}$.

La gran preocupación y, por encima del más o menos unitario carácter étnico o social, lo que realmente se perseguiría por ineludible es el desarrollo económico del continente. Sin este despegue hacia la gran industria (abandonando la prioritaria y básica, para la totalidad de los gobiernos, política agraria tradicional), Ugarte comprende que su idea de unificación sólo podía revestir para los ciudadanos de la gran América un carácter cultural. Por tanto, la Patria Grande debía contar con un gran mercado interno que, junto a la explotación de los recursos naturales y la implantación de un potente sector secundario, sacaran a América de las dificultades económicas y el atraso comercial en que se encontraba a comienzo de siglo; el establecimiento de líneas navieras americanas, el tendido de redes ferroviarias y la proliferación de medios de comunicación entre las distintas repúblicas americanas (fueron numerosas las ocasiones en que exteriorizó sus quejas por el predominio de información europea en periódicos americanos y el desconocimiento de aun los grandes sucesos de las propias repúblicas hermanas), eran las medidas que debían completar las necesidades iniciales. Pero la acción prioritaria era la consecución de la independencia económica del continente.

Este mercado único que tirara de la idea unionista, ¿podría realizarse constreñido y fragmentado en los estrechos marcos de cada uno de los países? Y lo que aun le preocupaba más: un continente colonizado durante siglos, que mantenía unos contactos comerciales «hacia afuera» en régimen de semi-colonia, únicamente con la exportación de materias primas, y «hacia adentro» en régimen desquebrajado e inconexo con mínimos intercambios efectivos ¿podía realizar ese despegue precisamente hacia la creación del gran mercado interior americano? A partir de este momento la idea de unificación, fundida con la pretensión de un Estado socioeconómico adelantado por medio del mercado interior, se liga a un tercer componente que por su omnipresencia y todopoder será tratado por Ugarte como el verdadero obstáculo hacia la unificación: el predomi-

\footnotetext{
9 «He pensado siempre que España debe representar para nosotros lo que Inglaterra para Estados Unidos: el antecedente, el honroso origen, la poderosa raíz de la cual fluye la savia primera del árbol. En medio de la desagregación política y en una etapa de cosmopolitismo inasimilado, para mantener el empuje y la hilación de nuestra historia, conviene no perder de vista el glorioso punto de partida, esa espina dorsal de recuerdos." El destino... op. cit.
} 
nio de potencias extranjeras sobre América, por Gran Bretaña y, principalmente, Estados Unidos.

\section{ANTIMPERIALISMO}

En 1899 Ugarte viaja por primera vez a Estados Unidos, México y Cuba, encontrando en su recorrido diferencias abismales entre los primeros y los países de tradición española. En un primer momento su razonamiento es sencillo: división frontal entre los ricos y desarrollados Estados Unidos del norte y los atrasados y paupérrimos estados balcanizados del sur ${ }^{10}$. Es esta reflexión sobre la diferencia del hecho descolonizador y sus dispares resultados lo que le hace ratificarse en su idea de la inevitabilidad de la unión. Llega a ella por medio de dos premisas: la existencia de dos esferas tan diferentes y tan cercanas hace que inexorablemente se establezca un enfrentamiento por el dominio de la más poderosa sobre la más débil (una vez que el papel de Europa se ha visto irremisiblemente disminuido); sólo se podrá hacer frente al avance frenético del poderoso vecino del norte reuniendo todos los artificiales países bajo el unitario pabellón natural americano. Así se pone de manifiesto desde el principio que la idea de la Patria Grande se ligaba estrechamente a la posesión de las respectivas soberanías nacionales (base irrenunciable de una supra-soberanía americana) y al necesario progreso económico y social mediante la potenciación del mercado interno. Al mismo tiempo que se teme a Estados Unidos, se persigue una reunión semejante a la suya; camino no sólo aconsejado, si no inevitable si en lugar del progreso no se quiere subsistir bajo el dominio exterior.

Durante el resto de su dilatada vida, Ugarte persiguió y denunció el imperialismo colonial (que él en numerosas ocasiones denominará «anglosajón», al ser Estados Unidos y Gran Bretaña, ésta ya en menor gra-

to "Contemplemos el mapa de América. Lo primero que salta a los ojos es el contraste entre la unidad de los anglosajones reunidos con toda la autonomía que implica el régimen eminentemente federal, bajo una sola bandera, en una nación única y el desmigamiento de los latinos, fraccionados en veinte naciones, unas veces indiferentes entre sí y otras hostiles». El porvenir de América Latina... op. cit. 
do, los participantes en la explotación de los recursos del continente). En 1901 publica El peligro yanqui, primera aproximación a la política exterior de Estados Unidos hacia América.

"La política exterior de los Estados Unidos tiende a hacer de la América Latina una dependencia y extender su dominación en zonas graduadas que se van ensanchando primero con la acción de la fuerza comercial, después con la política y por último con las armas» ${ }^{11}$.

Si su oposición a esta política había nacido por la intromisión en la guerra cubana y sus consecuencias, continuó aumentándose con la separación panameña, las humillaciones de Nicaragua, la invasión sobre México, las intervenciones en Santo Domingo, etc.; nunca faltaron causas. Tan sólo durante dos años, coincidiendo con la puesta en acción del New Deal, Ugarte se abstuvo de atacar y, muy al contrario, apoyó la Política de Buena Vecindad potenciada por F. D. Roosevelt ${ }^{12}$.

«El imperialismo norteamericano es el útil más perfecto de dominación que se ha conocido en las épocas", y esto es así según Ugarte debido a la flexibilidad de la acción exterior y a la diversidad de las for-

11 «El peligro yanqui", El País, 19-X-1901; recogida en La nación Latinoamericana... Op. cit.- Sobre la intervención militar - directa o indirecta- de Estados Unidos en América se realizan juicios que trascienden la época en que fueron escritos, llegando a describir el presente: "Cuando la revolución puede serles favorable, los imperialistas la provocan; cuando puede serles nociva, la hacen imposible. Tres hombres han querido oponerse en estos últimos tiempos al imperialismo: Porfirio Díaz en México, Cipriano Castro en Venezuela y Santos Celaya en Nicaragua. Los tres han sido derrotados por levantamientos alentados por los imperialistas de este país. No me digáis que eran tiranos que cayeron al peso de sus crímenes. Ningún político está tan desprestiguiado como el que rige los destinos de Guatemala y sin embargo el imperialismo lo sostiene, por que es su mejor apoyo en Centroamérica». [Se refiere a Manuel Estrada Cabrera, que durante dos décadas gobernó Guatemala]. Mi campaña hispanoamericana... Op. cit.

${ }_{12}$ Efectivamente Ugarte se vio impresionado por los cambios prometidos por la administración Roosevelt y su puestá en práctica, comenzando por la retirada de la enmienda Pratt: "Cesa como evidencia elocuente del fatídico monroismo de marras para devenir índice inequívoco de ese New Deal, cuyas implicaciones interamericanas toman formas concretísimas, que serán otros tantos testimonios de la sinceridad y pureza de objetivos del hombre que hoy con hoy manda en el altazano del capitolio estadounidense». M. UGARTE: "El Crepúsculo del Imperialismo Yanqui», Revista de las Españas, mayo-junio de 1934, pág. 257. Este entusiasmo no duró mucho, si bien después de estas fechas sus ataques contra la política exterior norteamericana no fueron tan abundantes ni duros. 
mas que adopta según las circunstancias ${ }^{13}$. Una vez acabada su expansión territorial (que en un primer momento Ugarte afirmó que seguiría --al igual que Texas, Sonora, California o Cuba - hasta completar el continente), la política de Estados Unidos inaugura un sistema de anexionarse riquezas sin los habitantes y las tierras que producen esas riquezas, desdeñando las apariencias exteriores para llegar al núcleo de la dominación sin el peso muerto de extensiones que administrar y masas que contener y dirigir. El modo en que esto llega a producirse se consigue mediante tres presiones progresivas: el martial spirit (tomádo como presión militar), la diplomacia del dólar y el control sobre la teórica dirección interior; el párrafo siguiente sintetiza su pensamiento a este respecto:

"La acción que se hace sentir en forma de presiones financieras, tutela internacional y fiscalización política, concede todas las ventajas $\sin$ riesto alguno. Es en el desarrollo de esta táctica donde ha evidenciado el imperialismo la incomparable destreza que sus mismas víctimas admiran. En el orden financiero tiende a acaparar los mercados con exclusión de toda competencia, a erigirse en regulador de una producción, a la cual pone precio, y a inducir a las pequeñas naciones a contraer deudas que crean después conflictos, dan lugar después a reclamaciones y preparan injerencias propicias a la extensión de la soberanía virtual. En el orden exterior se erige en defensor de esos pueblos, obligando al mundo a aceptar su intervención para tratar con ellos y arrastrarlos en forma de satélites dentro de la curva de su rotación. En el orden interno propicia la difusión de cuanto acrece su prestigio, ayuda las ambiciones de los hombres que favorecen su influencia y obstaculiza toda irradiación divergente, cerrando el paso de una manera perentoria a cuantos, más avisados o más patriotas, tratan de mantener incólume la nacionalidad" ${ }^{14}$.

El último punto trata sobre los que Ugarte denominó «el ideal del imperialismo: gobernar por manos ajenas", puesto que si las denuncias se efectúan frente a la política exterior de Estados Unidos, los últimos extremos de ésta se llevan a cabo mediante los propios gobiernos americanos; hacia éstos, ejecutores efectivos de los designios extranjeros, se vierten amargas reflexiones ${ }^{15}$. En el prólogo de la segunda edición de El

13 «Roma aplicó sistemas uniformes. España se obstinó en jactancias y oropeles. Hasta en nuestros propios días, Inglaterra y Francia se esfuerzan por dominar más que por absorber. Sólo Estados Unidos han sabido modificar el andamiaje de la expansión». Como la cita anterior en M. UGARTE: «El Imperialismo», Revista de las Españas, enero-febrero de 1930, pág. 3.

${ }_{14}$ Ibiden, pág. 4.

15 «Mientras la América Latina esté gobernada por políticos profesionales cuya única 
porvenir de la América Española (1920) se denuncian los ingenuos equilibrios que sincera o taimadamente se habían ido presentando por estos dirigentes. En primer lugar la negación del hecho, o cuando éste era demasiado flagrante, asegurar que la realidad de lo que se anuncia como «el peligro norteamericano» no existía; lo que hacía entrar seguidamente en una necesaria cadena de justificaciones y disculpas: las reiteradas invasiones de Nicaragua (aún no se había desatado el enfrentamiento contra Sandino, del que Ugarte fue portavoz apasionado en Europa) habían sido una necesidad para la estabilización de la zona; la intervención en México, una respuesta vigorosa a reiteradas provocaciones; el hecho panameño, un apoyo a la autodeterminación y un paso necesario para el progreso comercial; etc. ${ }^{16} \mathrm{El}$ segundo argumento expuesto era la obvia demostración de que las fronteras de los países respectivos no habían sido atacados, dejando sin preocupación lo que hubiera sucedido fuera por considerarlo ajeno a los intereses nacionales: dado que las políticas exteriores de los Estados se configuraban en su mayor parte en la dirección única que unía la capital respectiva con Washington, y del resto prácticamente sólo se conocía mediante las noticias del embajador norteamericano ante el Gobierno, éstas no podian ser mejores; la prueba de la sincera amistad de la "Hermana Mayor" hacia el país era "el ímpetu que les lleva a perjudicar a las repúblicas rivales ${ }^{17} \%$. El tercer argumento presenta un título muy conocido, pero tomado en pasiva a como fue enunciado: el destino manifiesto. ¿Era posible la resistencia a una fuerza tan superior? $Y$ en todo caso, ¿no era mucho mejor someterse y disfrutar

función consiste en defender los privilegios abusivos de la oligarquía local y en preservar los intereses absorventes de los imperialismos extranjeros, ninguna evolución puede ser posible. Se multiplicarán los espejismos, pero, en su ausencia, la sujección se agravará. «El nuevo Congreso Panamericano y la juventud», manifiesto en París, noviembre de 1933, en La nación latinoamericana; Caracas 1978, Biblioteca Ayacucho, 45.

${ }^{16}$ Al no haberse podido consultar la correspondencia privada de Ugarte no se tiene constancia de quiénes pudieron emitir tales opiniones y otras semejantes, ya que él nunca lo manifiesta; por otro lado, la excusas y justificaciones (que él ya toma de un modo crítico, incluso con una amarga burla) corresponden al espíritu de densos razonamientos de la propaganda de la Unión Panamericana; como ejemplo de estos entramados justificativos -y sin la necesidad del membrete de la Unión- puede consultarse E. GIL, Evolución del Panamericanismo: el credo de Wilson y el Panamericanismo; Buenos Aires 1933, Librería y Casa editorial de Jesús Menéndez.

${ }_{17}$ Sobre el sistema diplomático de los países americanos Ugarte escribió: «Basta observar las decisiones contradictorias de los gobiernos, la desafinación en las gesticulaciones, la elección del personal y la falta de simultaneidades oportunas, para comprender que hoy como ayer nos hallamos diplomáticamente en plena anarquía y que lo de Panamá, Nicaragua y Santo Domingo podrá repetirse mañana en cualquier latitud del Continente, sin que se desarrolle la menor acción conjunta». M. UGARTE: «El porvenir de la América Española», Unión lbero-Americana, noviembre de 1920, pág. 3. 
del bienestar y la abundancia que aseguraba el invasor que tratar de defender la miseria anárquica en que se vivía con certeza de ser barrido? Debía aceptarse el predominio norteamericano de buen grado, pues de lo contrario se debería acatarlo a la fuerza, y muy posiblemente tras haber sido apartados y suprimidos los que se habían resistido. Sobre estos argumentos Ugarte nada dice, dejando que las palabras ajenas obren su propia descalificación; pero sí sobre sus autores, ejecutores en su doble delito de una política ajena que tan sólo persigue mantener el estatus colonial. Doble delito pues, además de una sumisión servil, cierran el paso a otros que podrían hacer cambiar sustancialmente la situación; gobernantes opuestos a cualquier cambio que si no alcanzan la forma de frenar a los inquietos, si poseen la ayuda de los poderosos norteamericanos para mantener la situación ${ }^{18}$.

De qué medios disponía para hacer variar la situación, conseguir la perseguida independencia económica (y con ella la política, de facto) de las potencias coloniales. Ugarte propone, y comienza a ejecutar con su propaganda, tres medidas: la primera no es otra que la estudiada potenciación del movimiento unionista, y en este marco debe contemplarse la fundación en 1914 de la Asociación Latinoamericana ${ }^{19}$. El segundo medio es la apelación en busca de justicia, ante los mismos ciudadanos de Estados Unidos, por los acontecimientos ocasionados por su gobierno; publicó con cierta regularidad en varios de sus periódicos, exponiendo los puntos de vista conocidos ante la política exterior de Estados Unidos hacia América, pensamiento que sintetizó en sus conferencias en la Universidad de Columbia ${ }^{20}$. Al tercer medio ya se ha aludido cuando se

${ }^{18}$ Siguiendo la divisa adjudicada a Metternich («Hay que ayudar en Francia las ambiciones de $X$, porque $X$ es muy torpe y con él estamos tranquilos"), Ugarte afirma que "la consigna general ha sido empujar a los menos capaces, más que por las concesiones que de ellos se puedan arrancar, por los errores que ellos solos comenten, sin incitación de nadie». M. UGARTE: «El imperialismo»; Revisla de las Españas, enero-febrero de 1930, pág. 5.

${ }^{19}$ Ya en 1903 había propuesto una "vasta agrupación de americanos conscientes» bajo el nombre de Liga de la Solidaridad Hispanoamericana o Sociedad Bolívar. La Asociación Latinoamericana, fundada en Buenos Aires en 1914, desarrolló una intensa labor durante tres años, pero no consiguió mantenerse. A mediados de los años veinte Ugarte era Presidente de honor de la Unión Latinoamericana, también de Buenos Aires. En España, desde 1917 colaboró estrechamente con al Unión Ibero-Americana, publicando con asiduidad en sus revistas.

${ }^{20}$ «Yo pregunto a la opinión norteamericana si es justo que un gran pueblo, que ha contraído responsabilidades históricas, en vez de corregir el convulsionismo de los países vecinos permita que algunos de sus ciudadanos lo estén fomentando con todas sus fuerzas para poder decir al mundo: «¿No veis? ¡Sólo habrá aquí paz si dominamos nosotros!” ¿Es moral que un país que podía ser el educador de esas jóvenes democracias consienta en 
señaló el apoyo que los países europeos (España, Francia, Portugal e Italia, principalmente) debía realizar en favor del movimiento unionista y de liberación. El planteamiento de Ugarte incide en potenciar la vinculación económica y cultural con Europa para debilitar la mantenida con Estados Unidos; al no encontrarse estas naciones en condiciones de mantener una política de presión y colonizaje como la que aquéllos realizan, el producto sería una paulatina desvinculación de ambas entidades -Europa y Estados Unidos- hacia América.

\section{SOCIALISMO}

En lo expuesto hasta este punto, la estructura del pensamiento ugartiano -americanismo y antimperialismo- tiene claros paralelismos, encontrándose un grupo coetáneo de ensayistas que participan de las mismas inquietudes: Vargas Villa, Cesar Zumeta, José Rodó, Blanco Fombona, Ricardo Rojas, e incluso - hasta cierto punto- el mismo Rubén Darío. Lo que diferencia el pensamiento de Ugarte del de éstos, lo que ha hecho que sea sistemáticamente apartado de todo estudio y consideración (tanto en su país como en la generalidad americana y española, a pesar de la considerable fama que alcanzó en vida) y, paradójicamente, lo que hace que su entramado ideológico - a diferencia de los anteriores- posea una virtualidad claramente contemporánea, es la vinculación positivamenie satisfecha entre los conceptos estudiados - americanismo, antimperialismo- y una ideología dinámica con relieve en el presente: el socialismo. Mientras los dos conceptos anteriores en los autores de Ante los bárbaros, Eurindia, o Ariel están imbuidos de claros tintes liberales, no exentos de concesiones aristocráticas -el origen familiar arrastraba-, con las aportaciones más avanzadas en un positivismo matizado; incluso en Rodó y Rojas su disilusión les hará acogerse a un reaccionarismo instintivo, arropado por la espiritualidad en uno y el indigenismo en el segundo. Mientras tanto, Ugarte mantiene un nacionalismo populista, apostando decididamente por una democratización profunda del proceso político y por una socialización de los beneficios de la riqueza comercial.

que se las esté corrompiendo y anarquizando como un mal curador que fomenta en su pupilo la embriaguez y los vicios para minar su naturaleza, empujarlo al cementerio y apoderarse de su fortuna?" The future of Latin America, conferencia en la Universidad de Columbia, New York, 9 de julio de 1912; con el título de "Los pueblos del sur ante el imperialismo norteamericano" fue integrada en Mi campaña hispanoamericana... Op. cit. 
Manuel Ugarte tiene sus primeros contactos con el socialismo en su Buenos Aires natal, pero su acercamiento definitivo se produce tras visitar repetidamente la Casa del pueblo de París; lugar donde al tiempo que descubre la nueva ideología percibe los errores a que conducían un seguimiento ciego del dogmatismo y una repetición salmódica de máximas y clichés. Para él el socialismo era una declaración de principios personales y una ética ante la sociedad ${ }^{21}$. Pero sobre todo era un instrumento de análisis histórico y un proyecto de realización política, alejado de un sentimentalismo moral al convertirlo en una verdad científica, liberadora de los preceptos liberales sobre la importancia de la economía en la política, la cultura e incluso la religión.

Pero esta conversión al socialismo también encerraba problemas, tanto personales como de coherencia ideológica, máxime cuando su estudio del socialismo no había sido sistemático, leyendo algunas obras clásicas, pero sin conocer en profundidad el pensamiento de Marx o Engels. Su uso y utilización de los principios fundamentales de la teoría marxista, pero tratando de encontrar una solución adecuada a cada problema sin caer en el puntual seguimiento doctrínal o metedológico de la teoría, le ocasionaron rápidos enfrentamientos con sus compañeros franceses y argentinos. El problema radica en su deseo de hermanar el socialismo internacionalista - Los obreros no tiene patria-, elaborado para Estados europeos y por tanto no sujetos a colonialismo alguno, y un americanismo anticolonialismo con clara intención nacionalista unitaria ${ }^{22}$.

En este planteamiento incurría en dos flagrantes oposiciones a los seguidores nominales del socialismo: por un lado, toda defensa patriótica del nacionalismo, incluso para sus compañeros argentinos, era tratada de «traición» para la meta común universalista; por otro, eran abundantes los socialistas europeos que por esa época justificaban el colonialismo, si bien entendido al modo decimonónico (para gran desilusión de Ugarte, que así lo escuchará en los congresos de la II Internacional de Amsterdan y Stuttgart de labios nada sospechosos, como Bernstein o Van Kol).

21 «Nacido en el seno de una clase que disfruta de todos los privilegios y domina a las demás, me he dado cuenta, en un momento de mi vida, de la guerra social que nos consume, de la injusticia que nos rodea, del crimen colectivo de la clase dominante y he dicho, rompiendo con todo lo que me podía retener: yo no me mancho las manos. Yo me voy con las víctimas». La nación latinoamericana... Op. cit.

${ }^{22}$ Un conocimiento más profundo de la obra de Marx, concretamente de sus escritos sobre Irlanda, habría facilitado de modo considerable su trabajo. Por razones obvias no se conocían las futuras aportaciones que en este sentido elaboraron Lenin y Trotski, y cuando éstas se dieron, Ugarte ya había solucionado su dramática ecuación. 
Su caso no es aislado; varios integrantes de la generación del 900 argentina tienen contactos más o menos intensos con el socialismo, que acaban en todos los casos con rupturas y negaciones. Manuel Gálvez lo abandonó por un aristocratismo religioso tan distante: Ghiraldo -amigo de Ugarte desde la infancia - pasó al anarquismo, dada la «docilidad» del partido socialista en Argentina; José Ingenieros (hijo de Salvador Ingenieros, uno de los fundadores de la I Internacional), aunque menos decidido, fue el de planteamientos más cercanos a Ugarte, lo que se percibe claramente con su compañía en la Unión Latinoamericana, años después de haber abandonado el partido. El Partido Socialista fundado y dirigido en esa época por Juan B. Justo, estaba integrado por inmigrantes extranjeros y pequeño-burgueses que buscaban afianzar su mentalidad liberal; su radio de actuación era principalmente el área metropolitana de Buenos Aires y grupos minoritarios en varias ciudades del interior. Su izquierdismo se basaba en gran parte en un verbalismo airado de tintes revolucionarios y en un acatamiento a las directrices teóricas del socialismo internacional. Sus manifestaciones prácticas se circunscribían a ser el ala izquierda de la corriente populistas de la oligarquía, lo que unía a la tradición centralista la oposición dogmática a todo movimiento nacionalista.

La entrada de Uguarte en el socialismo le lleva por tanto a plantearse la compatibilización de éste con su defensa del nacionalismo americano y su lucha antimperialista. Si el internacionalismo proletario era una de las metas deseables del socialismo, ¿de qué modo hermanar esta premisa con la certeza de su lucha contra la influencia exterior en la dividida nación americana? De la solución a este planteamiento deviene la importancia y el mayor valor para una lectura de la obra ugartiana en las postrimerías del siglo $\mathrm{xx}$. La respuesta comienza con una serie de paralelismos: el socialismo es la justa arma de la clase oprimida contra la clase opresora; de igual modo puede ser una bandera de los pueblos sojuzgados frente a los imperios que los colonizan ${ }^{23}$. El ideal de realiza-

${ }^{23}$ La argumentación más concreta de este punto se encuentra en "Socialismo y Patria" capítulo de Manuel Ugarte y el Partido Socialista, documentos recopilados por un argentino. Buenos Aires 1914, Unión Editorial Hispanoamericana; que reproduce un artículo de La Vanguardia (2-VII-1908): «Por eso podemos decir que socialismo y patria no son enemigos, [...] y ese patriotismo es el que nos hace defender contra las intervenciones extranjeras. Todos los socialistas tienen que estar de acuerdo, porque si alguno admitiera en el orden internacional el sacrificio del pequeño al grande, justificaría en el orden social la sumisión del proletariado al capitalista, la opresión de los poderosos sobre los que no pueden defenderse". 
ción política, del que se ha hablado antes, y el ideal de justicia no podian ser distintos para los países explotados y para los explotadores; si era una la justicia internacional, ¿acaso debían ser mantenidos los derechos de los países opresores? Planteando el problema dentro de la ortodoxia marxista ya en 1901, si bien no logra resolver totalmente el dilema establecido, ya aparece la dirección que proseguirá la argumentación con posterioridad. Para Ugarte esta solución se encuentra fundamentalmente en el distinto tipo de sociedad establecida sobre el que operan los factores del cambio socialista. De ese modo el nacionalismo efectivamente tienen un carácter reaccionario cuando es el resultado del seguimiento vasallático al capitalismo colonial de los imperios, o sencillamente el sustento de la clase dominante en los países no colonizados europeos; pero muy al contrario, el nacionalismo enunciado desde las colonias - sea cual fuere el grado de declaración de éstas- es de carácter progresivo, ya que la más importante reivindicación, por su urgencia y necesidad, es la de la liberación nacional. Corolario de todo esto es la necesidad de todo socialista de participar en la lucha antimperialista, en favor de las colonias, ya que por un ejercicio de dejar hacer se fomenta indirectamente la expansión del sistema colonial; lo que conlleva como consecuencia directa la consolidación del capitalismo como sistema económico de ámbito mundial. Esta argumentación la ratifica haciéndoles decir a Marx, en su proclamación de una unión-confusión de países y razas, que tal propósito no se puede conseguir mediante el sometimiento de unas a otras; ese mundo anacional debe conseguirse por suma de elementos, no por absorción del conjunto dirigido por un solo elemento. Es por tanto lógico que Ugarte mantenga el punto de vista que potencia el internacionalismo positivo, pues cuando un imperialismo en crecimiento trata de absorver una nueva nación ese mismo internacionalismo no puede justificar un silencio cobarde, cómplice en su inacción.

Esta cuestión insoslayable sobre el tema nacional (debe recordarse que se habla hacia un territorio en estado de semi-colonia) necesita, según Ugarte, el apoyo de todos los elementos opuestos a esa situación dominante. Esto conduce a que no se rehuyan las alianzas con el programa nacional democráta, ya que una vez conseguidos los fines de éste (la independencia económica nacional, justicia social, creación de una economia productiva y un mercado autodefinido) se alcanzaría más fácilmente la implantación socialista. El planteamiento inverso: renuncia y oposición al nacionalismo, en virtud de un internacionalismo proletario o de una revolución social virulenta, conduciría de hecho a un pacto implícito con la clase gobernante, pacto encubierto bajo un verbalismo que sólo engañaría a quienes decía beneficiar. 
Esta toma de postura llevó a Ugarte a un enfrentamiento abierto con sus compañeros argentinos y europeos. Abandonó el partido en 1913 dando a la prensa un comunicado en el que expresó los puntos de diferencia ${ }^{24}$. Básicamente son cuatro los puntos que los socialistas argentinos mantienen y Ugarte combate: el antinacionalismo ya estudiado, antimilitarismo, antirreligiosidad y colectivismo. En síntesis: mantuvo que la clase militar como "brazo armado de la burguesía" era válido para Marx y la Europa capitalista que él conoció, pero en América no todas las fuerzas armadas eran antipopulares, encontrándose numerosos casos de lucha por la liberación nacional. Negar la posibilidad de ayuda del potente sector militar era contraproducente; el mismo caso que se producía al no discernir entre sacerdotes «a favor y contrarios del fortalecimiento popular»; prueba que en América el factor religioso no siempre es un elemento de atraso, muy al contrario, puede servir como factor de cohesión frenta a la infiltración cultural del colonialismo. Con respecto al dominio de la tierra, Ugarte no está a favor de un colectivismo radical; más al contrario, su experiencia directa de los grandes latifundios y las masas indígenas paupérrimas, le conducen a proponer una reforma agraria que distribuyera la tierra a las manos paralizadas.

Al hacer centrado su ideología en la dimensión nacionalista, su posicionamiento bordea un revisionismo con claros tintes socialdemócratas, huérfano del arsenal dialéctico del socialismo clásico, inexistente sobre el tema. Al no encontrarlo, Ugarte se niega a trasplantar mecánicamente los programas, teorías y tácticas generados por y para Europa, intentando enraizar en América un socialismo, en el que termina por renunciar al materialismo histórico y la colectivización de la propiedad, pero al que va suministrando las dimensiones específicas de lo que acabó siendo su objetivo en este campo: la revolución nacional.

Es por tanto a este entronque del socialismo, ya imbuido de antimperialismo, y el naciorialismo americano la nueva faceta que faltaba para llegar a conformar la gran aportación de Ugarte al pensamiento americanista. Ésta se dio al examinar las consecuencias que tendría el resultado del enfrentamiento entre la idea panamericana del dominio oficial de Estados Unidos sobre América y la concepción latinoamericana de reunión de la Gran América de tradición íbera: «La derrota de los latinos en

${ }^{24}$ La decisión de separarse del partido socialista lleva a Ugarte a publicar un "Manifiesto' en los principales periódicos bonaerenses (21-XI-1913); recogido en Manuel Ugarte y el Partido socialista... Op. cit. 
América marcaría el retroceso del ideal de solidaridad y un recrudecimiento del delirio capitalista que haría peligrar el triunfo de los más nobles propósios" ${ }^{25}$. En el caso contrario, que en los países colonizados - particularmente América - pueda introducirse una revolución nacional de carácter socialista, esto sería doblemente positivo: al marcar el punto de arranque en el proceso transformador del sistema atrasado y empobrecedor que el colonialismo mantenía en las tierras donde estaba implantado; en segundo lugar por que esta reacción exterior daría lugar a un inicio de debilidad del sistema imperialista, resquebrajamiento por el que se introduciría la crisis en los países colonizadores con claras oportunidades para el crecimiento e implantación del socialismo, posibilidades capidisminuidas por los magníficos resultados económicos de las rentas coloniales que hacían acallar la lucha de clases. La implantación del socialismo en América revertía así en beneficio de las clases inferiores de Europa y de los mismos Estados Unidos; era por tanto deseable que los socialistas de estos países apoyaran el movimiento de liberación americano.

A modo de conclusión podríamos señalar la importancia que la obra de Manuel Ugarte tuvo para las generaciones posteriores que continuaron intentando aunar el socialismo con el nacionalismo americano; anticipación histórica que ha tenido plasmación real en la mayoría de los movimientos populares de liberación en naciones del tercer mundo sometidas al colonialismo; procesos revolucionarios donde las cuestiones políticas y sociales se han ido resolviendo al unísono de modo interrelacionado. De igual modo, Ugarte se presenta como un adelantado y precursor de la izquierda nacional americana, contrario a los planteamientos dogmáticos de los coyunturales líderes teóricos y a la oligarquía políticoeconómica, intermediaria de mismo sistema colonial.

Ambos puntos han sido causantes de que la importancia de la obra ugartiana haya sido silenciada y apartada, encontrando muy escasos tratamientos y someros estudios. Pero también han sido los causantes de que llegue hasta el presente con una vigencia sin paralelo en los pensadores coetáneos; pues los problemas señalados y denunciados aún continúan ahí, encontrando en sus meditaciones y soluciones lúcidas respuestas aun a la luz de los acontecimientos contemporáneos: la división de América, la intervención directa e indirecta de Estados Unidos, la colonización económica, los desequilíbrios sociales...

\footnotetext{
${ }^{25}$ El porvenir de la América Latina... Op. cit.
} 